\title{
Study on Transcultural Communication of Culture of Traditional Chinese Medicine in Countries along One Belt One Road
}

\author{
Aixiang Huo, Qiang Wang \\ General center, Xi'an Peihua University, Xi'an 710125
}

Keywords: Culture of Traditional Chinese Medicine, Communication, One Belt One Road

\begin{abstract}
The culture of traditional Chinese medicine is a uniquely charming treasure of traditional Chinese culture as well as an important carrier of Chinese culture going global. The rich and profound universal value implied by it and its unique curative effect manifested in disease prevention and treatment have been widely accepted and are producing great attraction and appeal on other countries. Moreover, traditional Chinese medicine is an important carrier and resource factor of ancient Silk Road and has made contributions to the external exchange of China and health services of people in the world. Currently, state leaders such as General Secretary Xi Jinping and Premier Li Keqiang attach great importance to the external exchange and cooperation of traditional Chinese medicine and expect that traditional Chinese medicine can play a vital role in Go Out policy and OBOR strategy.
\end{abstract}

\section{International communication of culture of traditional Chinese medicine for promoting the improvement of national soft power}

In 1990, Joseph Nye, a professor in Harvard University, first developed the concept of Soft Power and divided comprehensive national power into hard power and soft power. Hard power is composed of resource strength, economic strength, military strength and scientific and technological strength. Soft power refers to invisible influence produced by a country through the attraction of political system, appeal of cultural value and appetency of national image, which makes other countries comply with its objectives and allows itself to get what it wants. Culture is the core content of soft power. Soft power in the narrow sense refers to cultural soft power. Joseph Nye considered that hard power is always limited and national power with unlimited tension is soft power. In the information era, soft power is becoming more prominent.

It happens that there is a similar case. When elaborating the development trend of international relation in the $21^{\text {st }}$ century in Clash of Civilizations and Reconstruction of World Order, famous American political scientist Huntington believed that the "hard power" era with simple pursuit for victory in military, economic and political struggles had passed and culture and civilization started to get involved in international competition as an important "soft power" and constituted fundamental and decisive factors for victory.

In the current era, culture is indeed becoming an important source of national cohesion and creativity and an important aspect of national comprehensive power. The proportion of American cultural industry in national economy ranked the $12^{\text {th }}$ twenty years ago and has risen to the $4^{\text {th }}$ now. American film and TV industry has become a foreign exchange earning industry among the top in USA and kept pace with its aerospace industry and modern electronics industry. 1/4 of 400 companies with the strongest strength in USA are cultural enterprises. Currently, USA has controlled the production and making of $75 \%$ TV programs in the world. Among TV programs in many countries, American programs often account for $60 \% \sim 70 \%$ and even over $80 \%$ in some countries. The total output of American films is only $6 \%$ of the output of films in the world. However, its overall share in the world film market has reached $80 \%$.

Some scholars think that American cultural penetration in the world is mainly manifested in its all-pervasive information products, fast food chain and Hollywood blockbuster. Its political ambition of dominating the world is undoubtedly hidden behind such commercial activities. It has earned money from other countries and meanwhile spread, confirmed and strengthened its value, belief and 
lifestyle in the world through the dumping of these products. All this will control the mind of some people and directly threaten the future and fate of other countries.

China was a powerful cultural country in the history. Chinese value, system civilization and artistic culture produced great attraction and influence on surrounding countries and even the world. Today, Chinese economy has developed rapidly and economic strength has improved significantly. GDP gross of China leaped to the second place in the world in 2011. China has been rated as the locomotive and engine of world economic development by western media. However, while affirming achievements of China, we should also be aware that China only exports TV set rather than TV program and China is not a real power, just as British Mrs Thatcher said. To realize great rejuvenation of Chinese nation, it is far from enough to improve hard power alone. It is also required to raise the construction of soft power to national strategic level, further strengthen external publicity and cultural communication, drive Chinese culture to the world, expand the international influence of Chinese culture and occupy a higher place in world culture so as to improve the comprehensive national strength of China.

The culture of traditional Chinese medicine is a uniquely charming treasure of traditional Chinese culture as well as an important carrier of Chinese culture going global. The rich and profound universal value implied by it and its unique curative effect manifested in disease prevention and treatment have been widely accepted and are producing great attraction and appeal on other countries. Moreover, traditional Chinese medicine is an important carrier and resource factor of ancient Silk Road and has made contributions to the external exchange of China and health services of people in the world. Currently, state leaders such as General Secretary Xi Jinping and Premier Li Keqiang attach great importance to the external exchange and cooperation of traditional Chinese medicine and expect that traditional Chinese medicine can play a vital role in Go Out policy and OBOR strategy. General Secretary and Premier have witnessed and supported the signing of Memorandum of Understanding in the field of traditional Chinese medicine between China and Kyrgyzstan, China and Ukraine and China and Hungary for several times as of the end of 2014. The State Administration of Traditional Chinese Medicine has concluded and signed 83 agreements of cooperation in the field of traditional Chinese medicine with foreign governments and regional organizations. Countries (regions) signing these agreements are mostly distributed along OBOR. Data show that the total volume of imports and exports of traditional Chinese medicines in countries along OBOR was nearly 2.08 billion US dollars in 2013, accounting for over 50\% of the volume of import and export of traditional Chinese medicine in China.

In particular, when meeting Margaret Chan - Secretary-General of WHO and attending a meeting of Shanghai Cooperation Organization, Chairman Xi Jinping respectively mentioned that "we should promote the combination of Chinese and western medicines and the overseas development of traditional Chinese medicine and drive more medical products produced in China to the international market" and "traditional medicine is a new field of cooperation among parties and China is willing to cooperate with each member state in the establishment of TCM medical organizations and make full use of traditional medical resources to serve the health of people in member states".

However, eastern and western cultures have great differences. Traditional Chinese medicine developed under eastern culture and western culture cannot communicate and integrate with each other very soon. Therefore, the culture of traditional Chinese medicine should go ahead of the rest so that traditional Chinese medicine can "go out".

\section{Status quo of international communication of culture of traditional Chinese medicine}

From the $7^{\text {th }}$ century to the $10^{\text {th }}$ century AD, traditional Chinese medicine was spread widely around the world with the prosperity of Tang and Song dynasties and became a main therapeutic theory and means in many places. The rapid development of western medicine produced impact on traditional Chinese medicine to a certain extent by the $19^{\text {th }}$ century. However, due to the increasingly prominent drug tolerance and toxic and side effects of chemical drugs, traditional medicine gained popularity 
among people in the world again with its specific safe, economical and humanized health care mode. In particular, its influence in various countries in the world has been further expanded since 1990s. So far, traditional Chinese medicine has spread to over 130 countries and regions in the world.

With the increasingly closer international social communication in recent years, external cultural transmission of traditional Chinese medicine has gained remarkable effects and traditional Chinese orthopedics and acupuncture and massage have gained wide attention and recognition of foreign scholars. However, due to abstract theoretical concepts of traditional Chinese medicine, it is very difficult for westerners knowing nothing about traditional cultural background of traditional Chinese medicine to understand traditional Chinese medicine deeply under the edification of deep-rooted western medical thought. In addition, inaccurate translation of traditional Chinese medicine produces negative influence on its transmission and exchange. It is a common phenomenon that foreigners do not understand Chinese, good doctors of traditional Chinese medicine do not understand foreign languages and translators of traditional Chinese medicine do not understand traditional Chinese medicine. Translation of traditional Chinese medicine becomes an important barrier of external communication of the culture of traditional Chinese medicine. Finally, traditional Chinese medicine is the product of medical practice of Chinese nation over thousands of years as well as the crystal of experience obtained from direct repeated application on people. This is entirely different from laboratory proofing of western medicine which runs through the process of animal experiment, clinical verification and marketing. Therefore, the effectiveness and safety of traditional Chinese medicine are doubted in clinical application. Under the influence of multiple aspects such as low degree of legitimation of traditional Chinese medicine, overseas transmission of culture of traditional Chinese medicine is still faced with low recognition degree and narrow extension scope.

\section{Study on countermeasures for overseas transmission of culture of traditional Chinese medicine}

\section{Use historical experience for reference and explore coherence point with cultural value of countries along OBOR}

Traditional Chinese medicine has been an important content of overseas cultural transmission of China since ancient times. To realize effective overseas transmission of culture of traditional Chinese medicine, it is required to first summarize the experience of overseas cultural transmission of traditional Chinese medicine in all ages from the historical perspective. In Sui and Tang dynasties, traditional Chinese medicine was an important content of study of Japanese and Korean ambassadors. Traditional Chinese medicine brought by Zheng He when he sailed West in Ming dynasty made contributions to the development and prosperity of traditional Chinese medicine in Southeast Asian regions. In overseas cultural transmission of traditional Chinese medicine today, we can learn the experience, seek for coherence point between the culture of traditional Chinese medicine and scientific and cultural value of countries along OBOR and achieve the purpose of strengthening overseas cultural transmission of traditional Chinese medicine.

\section{Pay attention to accurate translation of classical literatures about traditional Chinese medicine}

Since the emergence of the earliest extant classical literature about traditional Chinese medicine Inner Canon of Huangdi, a lot of classical literatures have emerged in the development history of traditional Chinese medicine, such as Shennong's Herbal, Treatise on Febrile and Miscellaneous Diseases, A-B Classic of Acupuncture and Moxibustion, Supplement to Valuable Prescriptions, Synopsis of Golden Chamber, Compendium of Material Medica and Correction of Errors of Medical Works, which were written by famous doctors in the history with great efforts according to their life experience. They are the treasury of theories about traditional Chinese medicine as well as weapons for guiding the clinic of traditional Chinese medicine and play an indelible historical role in the development and expansion of traditional Chinese medicine. To achieve international communication of the culture of traditional Chinese medicine, international communication of 
classical theories of traditional Chinese medicine is one of the important bridges. Therefore, accurate translation of classical literatures about traditional Chinese medicine is undoubtedly an effective way for international communication of the culture of traditional Chinese medicine. During the transmission of the culture of traditional Chinese medicine, the accuracy of information source, the value and significance of transmission contents, features of people receiving such information and cultural differences among races should be considered. Methods and skills should be used for accurate translation of classical literatures about traditional Chinese medicine so that the culture of traditional Chinese medicine is not distorted and foreign people receiving such information can understand it accurately. It is required to train and establish teams enthusiastic about the transmission of traditional Chinese medicine, make them have both the knowledge of traditional Chinese medicine and abilities of transmission and provide talent guarantee for transcultural transmission of traditional Chinese medicine. Many institutes of traditional Chinese medicine in China have strengthened the training of export-oriented talents of traditional Chinese medicine. Meanwhile, it is necessary to pay attention to the improvement of foreign language level of traditional Chinese medicine teachers and overcome language obstacles in transcultural transmission of traditional Chinese medicine.

\section{Learn experience of Confucius Institute and expand diversified international transmission routes of culture of traditional Chinese medicine}

China has established over 300 Confucius Institutes overseas, which have achieved good result in the popularization of Chinese and become a platform for showing and spreading excellent traditional culture of Chinese nation. Currently, the western society has gradually accepted traditional Chinese culture. To initiate a new mode of overseas transmission of traditional Chinese culture, it is required to make full use of this achievement and promote traditional Chinese medicine under the great upsurge of transmission of traditional Chinese culture. We can add contents of traditional Chinese medicine appropriately in the teaching of Confucius Institutes and gradually integrate elements of traditional Chinese medicine in the teaching process, which can not only enrich school-running contents of Confucius Institutes, but also contribute to the transmission of excellent traditional culture such as traditional Chinese medicine. On the one hand, we can integrate traditional Chinese medicine and Chinese language well in teaching, elaborate the essence of traditional Chinese medicine and spread the culture and knowledge of traditional Chinese medicine to the world better. On the other hand, Confucius Institutes can spread the culture of health preserving with traditional Chinese medicine through activities such as lecture, seminar, report, opening day and week of festivals in China, thus influencing local medical and health concepts. By penetrating into communities and the daily life of residents, it can achieve real-time exchange and feedback, improve the understanding of Chinese and the culture of traditional Chinese medicine in countries along OBOR and meanwhile produce subtle influence on local culture.

\section{Adhere to use film and television and network for visualization and multimedia of culture of traditional Chinese medicine}

Strong ability of communication and radiation is an important guarantee for soft power of the culture of traditional Chinese medicine. We can spread popular science work about the culture of traditional Chinese medicine, videos of famous masters in the culture of traditional Chinese medicine with profound social influence and classical medical books through original, real-time, rapid and interactive Internet publicity and promotion platform such as search engine, network news, blog, microblog, wechat, facebook, twitter and instagram so as to make the culture of traditional Chinese medicine accepted and recognized by the public overseas more easily and improve the soft power of the culture of traditional Chinese medicine.

\section{Improve quality and safety guarantee of traditional Chinese medicine products}

Due to the occurrence of medical negligence of traditional Chinese medicine in foreign countries, it is necessary to reestablish its good reputation in product quality and safety guarantee. Quality and 
safety are key to the existence of traditional Chinese medicine in countries along OBOR. Traditional Chinese medicine enterprises in China should learn and introduce pharmaceutical production and quality control system of foreign enterprises positively and establish strict specification on quality control of traditional Chinese medicine. It is required to use traditional Chinese medicine for disease prevention and treatment, improve the health of people in countries along OBOR, speak with facts and curative effect and make more people see the significant curative effect of traditional Chinese medicine and trust doctors of traditional Chinese medicine so as to promote the transmission and development of traditional Chinese medicine permanently.

Under the strategy of OBOR and "Going Out", as a multi-ethnic element of China and uniquely charming treasure in cultural heritage, the culture of traditional Chinese medicine should be innovated constantly in terms of communication mode and method according to different national conditions and cultural background in different countries and regions. It is required to make friends, understand and care about the world, join in different dialogue ranks, establish a lasting relation

among countries and people with peace and mutual benefit through multiple channels and drive Chinese culture to the world.

\section{Acknowledgments}

This paper is 2015 school-level subject funding project of Xi'an Peihua University, which name is Study on Transcultural Communication of Culture of Traditional Chinese Medicine in Countries along One Belt One Road (OBOR), No. PHKT20150708.

\section{References}

[1] Joseph S. Nye and translated by Zheng Zhiguo. Confusion in Hegemony of USA: Why Cannot USA Be a Law on Itself? Beijing: World Affairs Press, 2002:5-6.

[2] Joseph Nye and translated by Wu Xiaohui. Soft Power - Way of World Political Circle to Success. Beijing: Oriental Press, 2005:11.

[3] Cao Jingmin. Culture of Traditional Chinese Medicine for Improvement of National Soft Power. China Medical Herald, 2012 (10)

[4] Zhang Yanli, Study on Countermeasures for Wushu Cultural Transmission Carried by Confucius Institute. Journal of Chongqing Technology and Business University (Natural Science Edition), 2010, (6). 